\title{
Design of Optimized Transition Width Linear Phase FIR Filter using PSO Algorithm with Constriction Factor Approach
}

\author{
Neha \\ M. Tech. Scholar \\ Electronics \& Communication Department \\ SLIET, Longowal
}

\author{
Ajay Pal Singh \\ Associate Professor \\ Electronics \& Communication Department \\ SLIET, Longowal
}

\begin{abstract}
Digital filters are an integral part of today's electronic industry. Finite Impulse Response (FIR) filters, a type of digital filter have found its use in vast number of applications due to their inherent nature of phase linearity and constant delay. But it has the disadvantage of requirement of large computational power and memory to achieve the same sharpness or cutoff that an Infinite Impulse Response (IIR) filter have. The present article aims on achieving an FIR filter with reduced transition width with the requirement of lesser computational elements. The evolutionary algorithm of Particle Swarm Optimization (PSO) is used for this case. The linear phase FIR filter is designed for high pass (HP) and band pass (BP) case in this article. The simulation results achieved transition width as low as 0.040 (HP) and 0.029 (BP) for the FIR filter designed with order 30 and 40 respectively.
\end{abstract}

\section{General Terms}

Filter Design, PSO with Constriction factors.

\section{Keywords}

Convergence, FIR filter, PSO, Transition width.

\section{INTRODUCTION}

Finite Impulse Response filters as the name suggests are the kind of digital filters for which the impulse response is finite. These filters are also called non-recursive as they generally do not have any feedback associated with them. FIR filters have the preferable characteristics of ease of implementation, high computational efficiency, less system complexity and most importantly the phase linearity. These characteristics have attracted the use of FIR filters in many filtering or digital signal processing applications $[1,2]$.

A digital FIR filter is designed with the aim to provide the solution which satisfies all the conditions for practical applications. Researchers designed different techniques for reduction of noise from signal and improved efficiency of the signal. The most traditional and straightforward approach to FIR filter design is to obtain a finite length impulse response by truncating an infinite duration impulse response sequence. It is obtained by taking product of ideal response with a window function and is called window method [3]. This method is fast and convenient but it does not allow controlling the approximation errors in different bands and hence suboptimal. In frequency sampling (FS) design technique, the fact that system function for digital filter to be designed can be obtained from the samples of the discrete Fourier transformed frequency response, is used. In practice at most two samples needs to be optimized to obtain the largest minimum stopband attenuation. The solution of the problem is available in the form of tables of transition values [4]. The FS technique has the advantages that more effective narrow band filters can be designed with arbitrary responses. However, these techniques do not have a sufficient control over the transition band frequency samples. Furthermore, calculation of filter coefficient at the sampling points is very tiresome and prone to errors. The best suited traditional method for exact linear phase FIR filter design is the Parks and McClellan (PM) minimax algorithm [5]. A computer program has been developed by Thomas Parks and James McClellan for the digital FIR filter design [6]. The design algorithm used a weighted error function in the absolute difference form. Such procedures yield filters which are optimal in the sense of approximating as closely as possible to desired frequency response. This method used to be the dominant method for optimum design of FIR filters due to its flexibility and computational efficiency until the development of traditional optimization techniques. The Steepest-descent method of optimization [7] can approximate any kind of frequency response for linear phase FIR filter but the transition width is to be compromised which is not acceptable. The other classical gradient based optimization methods are not suitable for FIR filter optimization because of problem of convergence to local optimal solutions, algorithm complexity and the requirement of continuous and differentiable objective function.

As filter design is a multimodal optimization problem, continuous efforts have been made for finding a solution to this problem of optimal filter design. Evolutionary optimization techniques as Genetic Algorithm [8], Simulated Annealing (SA) [9], Tabu Search [10], Artificial Bee Colony optimization [11], Differential Evolution [12] are implemented for the design of optimal digital filters and proved to be quite efficient by providing better control of performance parameters in addition to high stopband attenuation. Heuristic optimization technique of Genetic Algorithm (GA) gives efficient results for local optimum but is not very successful in determining global optimum and is also considerably slow. This article presents the use of the stochastic evolutionary optimization technique called Particle Swarm Optimization (PSO) for design of digital FIR filters with better parameter control \& to better approximate the ideal filter. The PSO technique is developed by Kennedy and Eberhart [13] simulating the social behavior of swarm of birds searching for a corn field. This optimization method requires no gradient and achieves a global optimal solution for the 
given multimodal objective function minimization in digital design problems. Several modifications of the conventional PSO also exist. Quantum-behaved PSO is a novel algorithm based on the quantum behavior of particles [14]. Luitel et al. [15] proposed the use of PSO with differential evolution for design of optimal filter. The method converges faster but with higher value of passband ripples. The evolutionary technique of differential evolution based on reserved gene presents an alternative for the design of optimum digital filters but the resulting transition width is large [16]. The technique of PSO with different velocity vector and swarm updating rule, called NPSO is defined in [17] but the resulting filter has large ripples in the passband region. Earlier, authors have used the technique of PSO for design of linear phase low pass FIR filter with smaller ripples in the passband as well as stopband [18]. But it is achieved at the expense of increased transition width.

Filter design methods presented so far are unsuitable for highly frequency selective applications, for example, biomedical or control systems. Further for the design of FIR filters with sharp transition at cutoff frequency, large number of filter coefficients is required. This requires an increase in the order of the filter to a considerable higher extent which increases system complexity as well as response time. To counter the problem, present article aims at designing the linear phase FIR filter of optimum length having sharp transition from passband to stopband and vice-versa using the technique of PSO with constriction factor approach. This may be achieved at the expense of slightly larger ripples in stopband but the resultant filter order requirement is quite low. The rest of the article is organized as: Section II defines the basic mathematics involved for the design of linear phase FIR filter for high pass and band pass case. Section 3 presents a brief description of PSO algorithm with the inclusion of constriction factor parameter. Also the basic design procedure steps are given in this section. Section 4 describes the design filter specifications and the simulation results obtained for all the considered cases. Finally section 5 briefly concludes the article.

\section{PROBLEM FORMULATION}

The transfer function of a digital FIR filter is given as:

$\mathrm{H}(\mathrm{z})=\sum_{\mathrm{n}=0}^{\mathrm{N}} \mathrm{h}(\mathrm{n}) \mathrm{z}^{-\mathrm{n}}$

where $h(n)$ represents the impulse response of the filter and $N$ is the order of the filter having $\mathrm{N}+1$ number of coefficients. Also the frequency response will be of the form as:

$H_{d}\left(e^{j \omega}\right)=\sum_{n=0}^{N} h[n] e^{-j \omega n}$

This article presents the design of even order linear phase FIR filter for the High Pass (HP) and Band Pass (BP) case. The impulse response $h(n)$ is considered to be positive even symmetric. The number of coefficients required are $\mathrm{N}+1$ but because of the symmetrical nature of $h(n)$, the dimension of problem is halved. The desired frequency response for the two cases can be defined as follows:

$\mathrm{H}_{\mathrm{i}}\left(\mathrm{e}^{\mathrm{j} \omega}\right)= \begin{cases}0 & \text { for } 0 \leq \omega \leq \omega_{c} \\ 1 & \text { otherwise }\end{cases}$

for HPF and

$H_{i}\left(e^{j \omega}\right)=\left\{\begin{array}{cc}1 & \text { for } \omega_{c 1} \leq \omega \leq \omega_{c 2} \\ 0 & \text { otherwise }\end{array}\right.$ for the case of BPF. Here $\omega_{c}$ is the cutoff frequency for FIR filter of HP case and $\omega_{\mathrm{c} 1}$ and $\omega_{\mathrm{c} 2}$ are the lower and upper cutoff frequency respectively for the FIR filter of BP case.

The approximate error function defining the difference between ideal and approximate filter is defined in ParksMcClellan algorithm [5] as:

$E(\omega)=G(\omega)\left[H_{i}\left(e^{j \omega}\right)-H_{d}\left(e^{j \omega}\right)\right]$

where $H_{i}\left(e^{j \omega}\right)$ is the ideal frequency response and $H_{d}\left(e^{j \omega}\right)$ is the frequency response of the designed approximate filter; $G(\omega)$ represents the weighing function used to provide independent control of the parameters $\delta_{\mathrm{p}}$ and $\delta_{\mathrm{s}}$ for the approximate error in the two frequency bands. For this article $G(\omega)$ is chosen to be unity for both of the frequency bands.

For achieving the designed filter response as close as possible to the ideal one, here the error fitness function is defined as the total squared error across the whole frequency domain. The mathematical form is given below:

$\operatorname{Fitness}(\mathrm{f})=\sum_{\omega} \operatorname{abs}(|\mathrm{E}(\omega)|)^{2}$

also the Eq. (2.6) can be rewritten as:

$$
\mathrm{f}=\sum_{\omega} \operatorname{abs}\left\{\left|\left[\mathrm{H}_{\mathrm{i}}\left(\mathrm{e}^{\mathrm{j} \omega}\right)-\mathrm{H}_{\mathrm{d}}\left(\mathrm{e}^{\mathrm{j} \omega}\right)\right]\right|\right\}^{2}
$$

The minimization of this error fitness function using the method of PSO with constriction factor approach is the objective here. Unlike other fitness functions that only consider the maximum value of the errors used for filter optimization, Eq. (2.6) reduced the problem to minimization of summation of all squared error across whole frequency domain, thus yielding FIR filters with sharp transition bands and optimum stopband attenuation.

\section{PARTICLE SWARM OPTIMIZATION (PSO) ALGORITHM}

PSO originally proposed by Kennedy and Eberhart is a global evolutionary optimization technique with implicit parallelism [13]. It is a robust population based stochastic search technique capable of handling non differential objective functions, unlike traditional optimization methods. The PSO algorithm is developed through simulation of birds flocking in multidimensional complex space in the search of food. Similarly in filter design problem, the algorithm is initialized with a population of random candidate solutions, conceptualized as particles. Each particle is assigned a randomized velocity and is iteratively moved through the problem space. This problem space is updated by applying some kind of operators according to the fitness information obtained from given problem statement to be simulated so that the individuals of the population can be expected to reach better solution areas. It moves iteratively towards best fitness position obtained so far by the individual itself (cognitive part) and by the whole population (social part).

The position and velocity associated with each particle are arranged in a form of matrix. For the $i^{\text {th }}$ particle it can be given as:

$$
\begin{aligned}
p_{\mathrm{i}} & =\left[\mathrm{p}_{\mathrm{i} 1}, \mathrm{p}_{\mathrm{i} 2}, \ldots, \mathrm{p}_{\mathrm{iD}}\right] \\
\mathrm{v}_{\mathrm{i}} & =\left[\mathrm{v}_{\mathrm{i} 1}, \mathrm{v}_{\mathrm{i} 2}, \ldots, \mathrm{v}_{\mathrm{iD}}\right]
\end{aligned}
$$

The length of the vector $\mathrm{D}$ represents the dimensions of the specified problem with $(\mathrm{i}=1,2, \ldots, \mathrm{N})$ specifying the population set of the particles. A fitness function is evaluated 
for all swarm particles and optimization of this fitness function is the aim, like a swarm of birds flocking stops when they found the food. For the fitness function optimization the position and the velocity of the particle is updated according to the individual best and social best results (as defined above) found so far according to the equations:

$$
\begin{aligned}
& \mathrm{v}_{\text {id }}{ }^{\mathrm{t}+1}=\chi\left[\mathrm{v}_{\text {id }}{ }^{\mathrm{t}}+\mathrm{c} 1 * \mathrm{r} 1() *\left(\text { pbest }_{\text {id }}-\mathrm{p}_{\text {id }}\right)+\mathrm{c} 2 * \mathrm{r} 2() *\right. \\
& \left(\text { pbest }_{\mathrm{gd}}-\mathrm{p}_{\text {id }}\right) \\
& \mathrm{p}_{\text {id }}{ }^{\mathrm{t}+1}=\mathrm{p}_{\text {id }}{ }^{\mathrm{t}}+\mathrm{v}_{\mathrm{id}}{ }^{\mathrm{t}+1}
\end{aligned}
$$

The superscripts $t$ and $t+1$ denote the index of previous and next iterations, respectively. $\mathrm{c} 1$ and $\mathrm{c} 2$ are the constriction coefficients, used normally to be 2.05. r1( ) and r2( ) in Eq. (3.3) specifies the random numbers uniformly distributed from 0 to 1 updated every time they occur. The factor $\chi$ called constriction factor is defined in [19] and is given by the formula below:

$$
\chi=\frac{2}{\left|2-\varphi-\sqrt{\varphi^{2}-4 \varphi}\right|}, \quad
$$

This velocity update equation specified in Eq. (3.3) uses constriction factor method and thus convergence is independent of the iteration cycles. For each iteration of the algorithm particles are moved according to Eq. (3.3) and (3.4) keeping within a bound of maximum velocity specified as $\mathrm{v}_{\max }$ for the evaluation of particle fitness for this new position and velocity during the iterative process. The steps for the PSO algorithm as employed for FIR HP and BP filter design case is provided in Table 1 . The best filter coefficient value hgbest $(\mathrm{N} / 2+1)$ is used for forming the complete filter response coefficients $(\mathrm{N}+1)$ by copying them due to phase linearity of the filter. Frequency and the magnitude spectrum are generated from this complete filter coefficient vector. The algorithm procedure to be followed for the given design problem is defined step by step in the table below:

\section{Table 1: Design Procedure}

Step 1. Define filter parameters to be used for designing linear phase FIR filter:

For High Pass (HP) case, stopband edge frequency, $\omega_{s}=0.25$; passband edge frequency, $\omega_{p}=0.3$.

For Band Pass (BP) case, passband edge frequencies, $\omega_{p 1}=0.2$, $\omega_{p 2}=0.3$; stopband edge frequencies, $\omega_{s 1}=0.15, \omega_{s 2}=0.35$. for both the cases stopband and passband ripple, $\delta_{p}=\delta_{s}=0.1$; and the order of filter, $\mathrm{N}=30$ and 40 is used.

Step 2. Define initial parameters of the algorithm which include particle population, $\mathrm{N}_{\mathrm{p}}=30 / 40$; dimensional size, $\mathrm{D}=16 / 21$ $(\mathrm{N} / 2+1)$; minimum and maximum value for filter coefficients, $\mathrm{h}_{\max }=1 ; \mathrm{h}_{\min }=-1$; velocity range, $\mathrm{v}_{\max }=0.1 ; \mathrm{v}_{\min }=0.01$; maximum no. of iterations, itmax $=350$.

Step 3. Generate initial set of filter coefficient values using above defined parameters.

Step 4. Deduce error fitness value for the whole population set using Eq. (2.5) and (2.6).
Step 5. Calculate the minimum fitness value obtained by each individual and by the whole population so far. Put the results in $\mathrm{h}_{\text {ibest }}$ and $\mathrm{h}_{\text {gbest }}$ vectors respectively.

Step 6. Update velocity and position of each coefficient vector using Eq. (3.3) and (3.4). Repeat Step 4 and 5.

Step 7. If value of vectors $h_{\text {ibest }}$ and $h_{\text {gbest }}$ calculated in Step 5 are better than those obtained in Step 6, modify the vector values and no change if otherwise.

Step 8. Iterate continuously from Step 4 to step 7 until a convergence criteria is met which may be reaching maximum no. of iteration or minimum error fitness value or a timeout condition.

Step 9. Design the desired filter by taking the $\mathrm{h}_{\text {gbest }}$ vector as the coefficients of optimized FIR filter. For the linear phase FIR filter of order $\mathrm{N}$, the complete response coefficients $(\mathrm{N}+1)$ are formed by replicating the $\mathrm{N} / 2+1$ coefficients of $\mathrm{h}_{\text {gbest }}$ vector.

\section{RESULTS AND OBSERVATIONS}

The MATLAB simulation is performed for the design of proposed linear phase FIR filter. Two design cases are considered. This includes design of HP and BP FIR filter for order 30 and 40 and hence the number of filter coefficients is 31 and 41 respectively. The designed filter aims at achieving the ideal filter characteristics for which the cutoff frequency is defined as:

$\omega_{\mathrm{c}}=\frac{\omega_{\mathrm{p}}+\omega_{\mathrm{s}}}{2}$

As defined in Table 1, the linear phase FIR filter for the two cases is designed for the transition width of 0.05 . The PSO algorithm is executed for 100 trial runs for both cases and the best and average results are recorded. All the simulations are performed with number of samples taken to be 128 .

The best optimized coefficients for the designed HP and BP filter of order 30 and 40 are given in Table 3 and 5 respectively.

Case 1: The PSO algorithm is applied for the design of FIR filter of order 30 . Fig. 1,2 and 3 demonstrates the experimental results. The magnitude response of the HP and BP filter designed is shown in Fig. 1 and the gain plot is shown in Fig. 2. The response parameters are as given in Table 2. It represents the transition width of designed HP and BP filter to be $0.040 \mathrm{~Hz}$ and $0.045 \mathrm{~Hz}$ respectively. Thus the designed filter fulfills the objective of sharp transition width requirement. The other parameters include stopband attenuation of $23.5 \mathrm{~dB}$ and $23.3 \mathrm{~dB}$, normalized passband ripples of magnitude 0.098 and 0.116 for the $\mathrm{HP}$ and $\mathrm{BP}$ filter respectively.

Fig. 3 shows the convergence profile for HP and BP FIR filter designed for order 30 . The algorithm converges for a small number of iterations giving the desired results in an average time span of 8.358222s and 8.329723s for HP and BP filter respectively. 


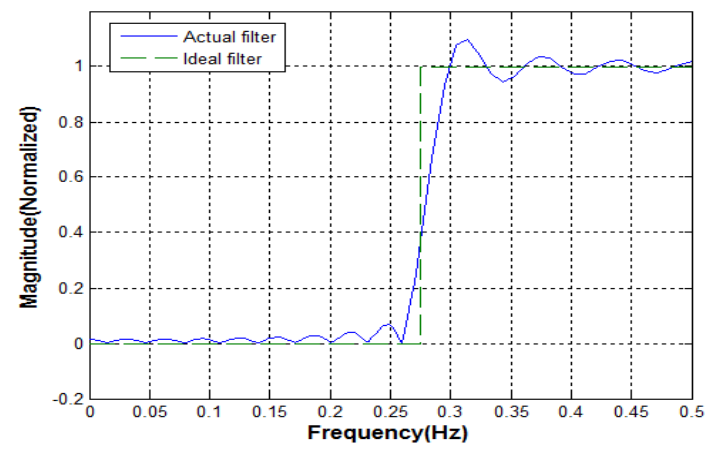

(a)

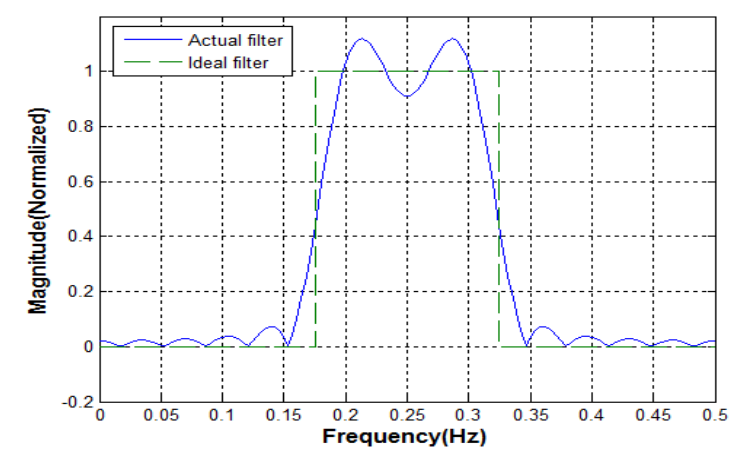

(b)

Fig. 1: Magnitude plot for linear phase (a) HP and (b) BP FIR filter of order 30

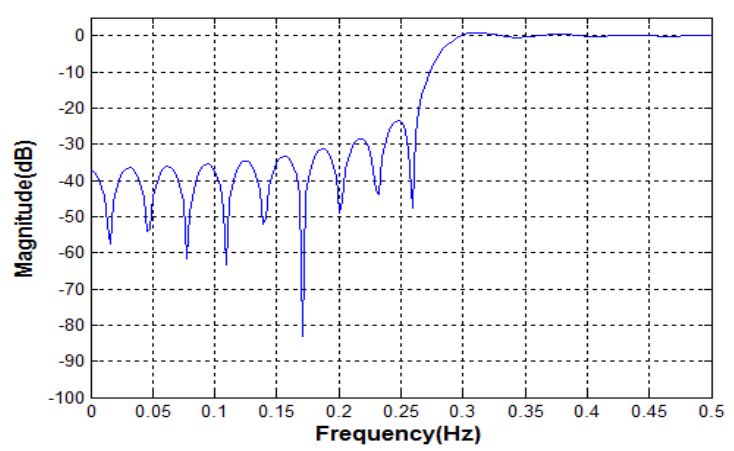

(a)

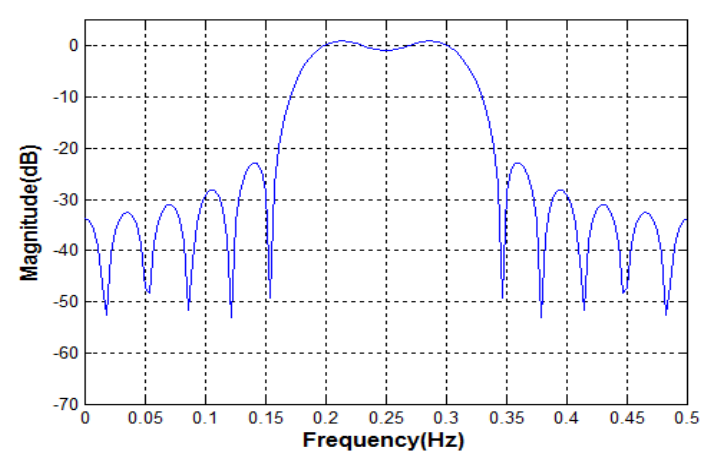

(b)

Fig. 2: Gain (dB) plot for linear phase (a) HP and (b) BP FIR filter of order 30

Table 2: Performance parameters for linear phase FIR filter of order 30

\begin{tabular}{|c|c|c|c|c|c|c|c|c|}
\hline \multirow[t]{2}{*}{$\begin{array}{c}\text { FIR Filter } \\
\text { Type }\end{array}$} & \multicolumn{3}{|c|}{$\begin{array}{c}\text { Passband ripple } \\
\text { (Normalized) }\end{array}$} & \multicolumn{3}{|c|}{ Stopband Attenuation (dB) } & \multirow[t]{2}{*}{$\begin{array}{l}\text { Transition } \\
\text { Width }\end{array}$} & \multirow{2}{*}{$\begin{array}{c}\text { Average } \\
\text { Execution } \\
\text { Time (s) }\end{array}$} \\
\hline & Maximum & Mean & $\begin{array}{l}\text { Standard } \\
\text { Deviation }\end{array}$ & Maximum & Mean & $\begin{array}{l}\text { Standard } \\
\text { Deviation }\end{array}$ & & \\
\hline HPF & 0.098 & 0.098 & $1.38778 \mathrm{E}-17$ & 23.6 & 23.5 & $1.0045 \mathrm{E}-15$ & 0.040 & 8.358222 \\
\hline BPF & 0.116 & 0.116 & $1.38778 \mathrm{E}-17$ & 23.3 & 23.3 & 0 & 0.045 & 8.329723 \\
\hline
\end{tabular}

Table 3: Optimized coefficients for linear phase FIR filter of order 30

\begin{tabular}{|c|c|c|}
\hline $\mathbf{h}(\mathbf{n})$ & Coefficients for HPF & Coefficients for BPF \\
\hline $\mathrm{h}(1)=\mathrm{h}(31)$ & -0.0190993632406702 & $1.95264438231729 \mathrm{E}-07$ \\
\hline $\mathrm{h}(2)=\mathrm{h}(30)$ & 0.00917239043467272 & -0.00318934798069316 \\
\hline $\mathrm{h}(3)=\mathrm{h}(29)$ & 0.0185976239953364 & $-2.77183343256512 \mathrm{E}-07$ \\
\hline $\mathrm{h}(4)=\mathrm{h}(28)$ & -0.0204573092948133 & -0.037253041209907 \\
\hline $\mathrm{h}(5)=\mathrm{h}(27)$ & -0.0124458631709172 & $5.22086225361872 \mathrm{E}-07$ \\
\hline $\mathrm{h}(6)=\mathrm{h}(26)$ & 0.030150051323387 & 0.0633711204020756 \\
\hline $\mathrm{h}(7)=\mathrm{h}(25)$ & 0.00265188580771194 & $1.13924314124764 \mathrm{E}-06$ \\
\hline $\mathrm{h}(8)=\mathrm{h}(24)$ & -0.0392766858556119 & -0.0414662773939917 \\
\hline $\mathrm{h}(9)=\mathrm{h}(23)$ & 0.0137634544025133 & $5.73351689311939 \mathrm{E}-08$ \\
\hline $\mathrm{h}(10)=\mathrm{h}(22)$ & 0.0464721843204722 & -0.0380002227247952 \\
\hline $\mathrm{h}(11)=\mathrm{h}(21)$ & -0.039273253037165 & $7.08593138271967 \mathrm{E}-07$ \\
\hline $\mathrm{h}(12)=\mathrm{h}(20)$ & -0.0523735462279436 & 0.153030268134104 \\
\hline $\mathrm{h}(13)=\mathrm{h}(19)$ & 0.091212883619916 & $-1.38354889811328 \mathrm{E}-06$ \\
\hline $\mathrm{h}(14)=\mathrm{h}(18)$ & 0.0556434075440816 & -0.254150049037975 \\
\hline $\mathrm{h}(15)=\mathrm{h}(17)$ & -0.312981559259612 & $-2.49696003597978 \mathrm{E}-07$ \\
\hline $\mathrm{h}(16)$ & 0.442902808786362 & 0.294831794709757 \\
\hline
\end{tabular}




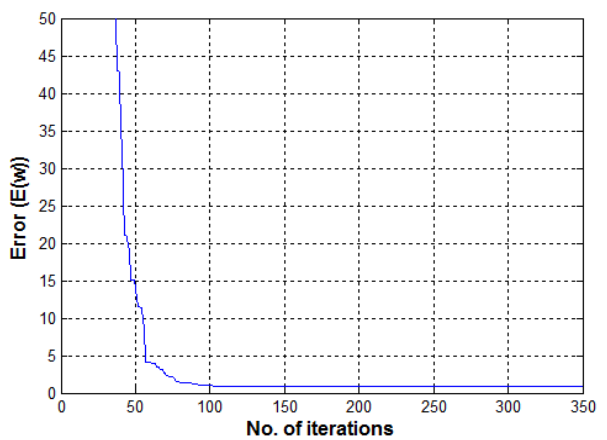

(a)

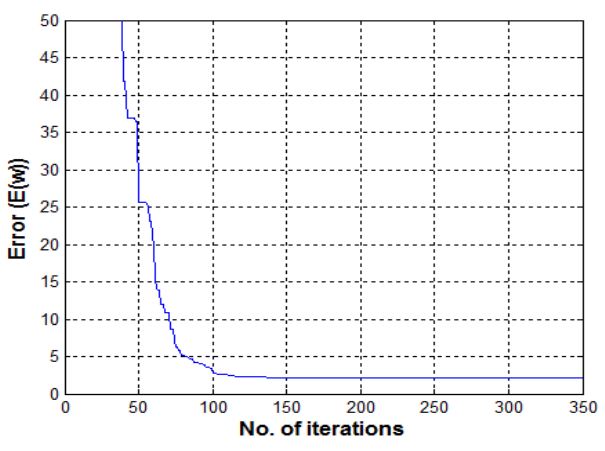

(b)

Fig. 3: Convergence behavior of PSO for linear phase (a) HP and (b) BP FIR filter of order 30

Case 2: For this case, the PSO algorithm is applied for the design of FIR filter of order 40. Fig. 4, 5 and 6 demonstrates the experimental results. The magnitude response of the HP and BP filter designed is shown in Fig. 4 and the gain plot is shown in Fig. 5. From the results of Fig. 4 and 5 it can be concluded that the response parameters improve with the increase of filter length. The response parameters are as given in Table 4. It represents the transition width of designed HP and BP filter to be $0.031 \mathrm{~Hz}$ and $0.029 \mathrm{~Hz}$ respectively. The

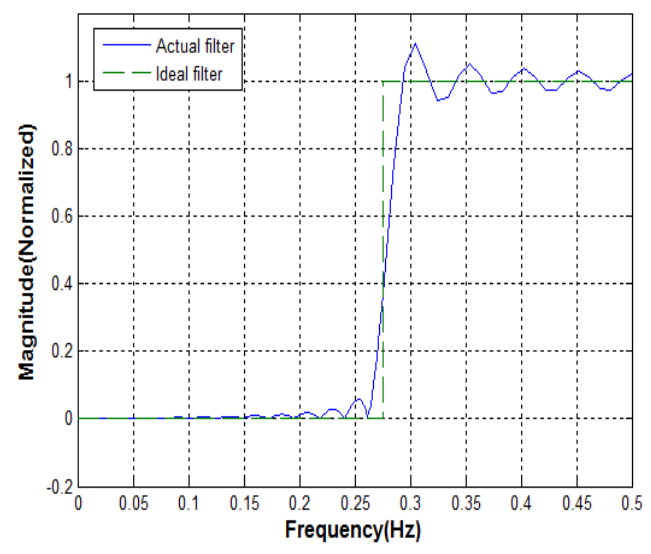

(a) other parameters include maximum stopband attenuation of $25.2 \mathrm{~dB}$ and $24.8 \mathrm{~dB}$, maximum passband ripples of magnitude 0.110 and 0.112 for the $\mathrm{HP}$ and $\mathrm{BP}$ filter respectively.

Fig. 6 shows the convergence profile for HP and BP FIR filter designed for order 40 . The algorithm converges for a small number of iterations giving the desired results in an average time span of $8.746373 \mathrm{~s}$ and $8.756441 \mathrm{~s}$ for HP and BP filter respectively.

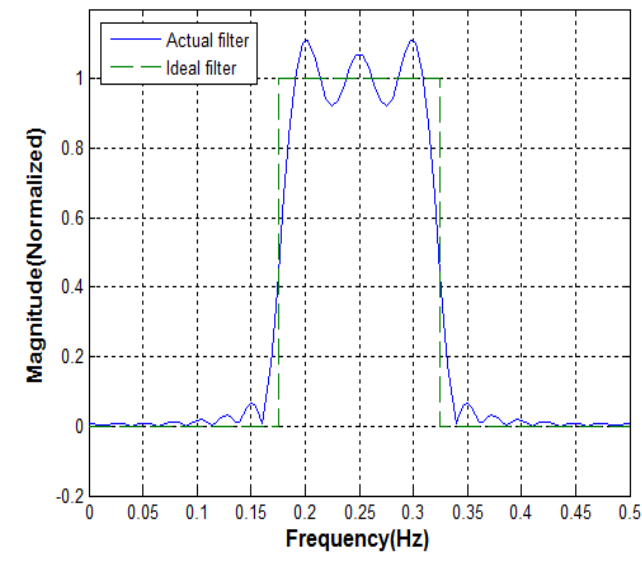

(b)

Fig. 4: Magnitude plot for linear phase (a) HP and (b) BP FIR filter of order 40

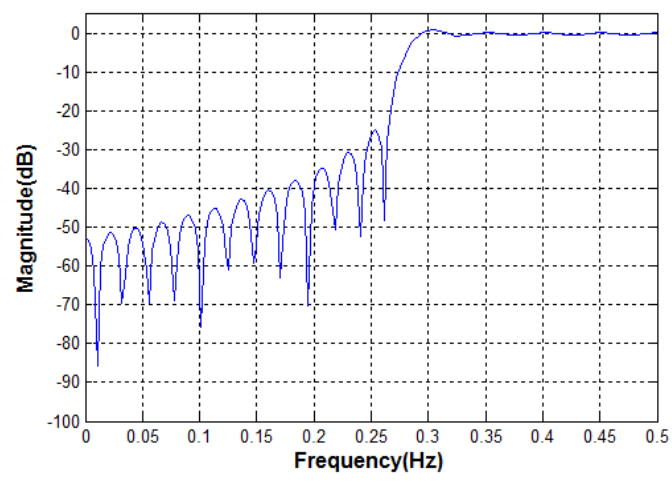

(a)

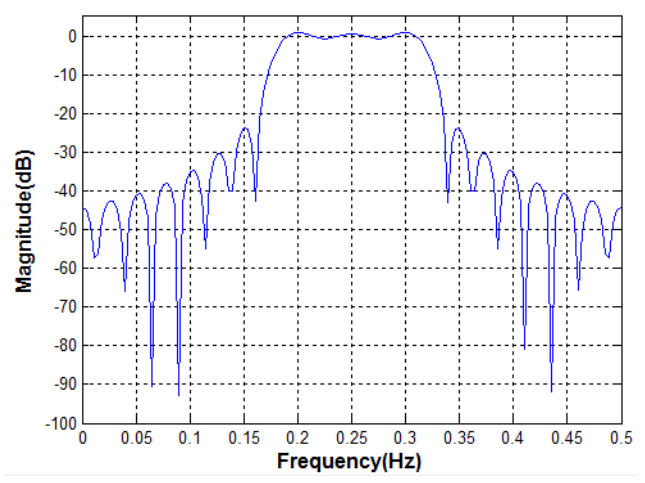

(b)

Fig. 5: Gain (dB) plot for linear phase (a) HP and (b) BP FIR filter of order 40 
Table 4: Performance parameters for linear phase FIR filter of order 40

\begin{tabular}{|c|c|c|c|c|c|c|c|c|}
\hline \multirow[t]{2}{*}{$\begin{array}{c}\text { FIR Filter } \\
\text { Type }\end{array}$} & \multicolumn{3}{|c|}{$\begin{array}{l}\text { Passband ripple } \\
\text { (Normalized) }\end{array}$} & \multicolumn{3}{|c|}{ Stopband Attenuation (dB) } & \multirow[t]{2}{*}{$\begin{array}{l}\text { Transition } \\
\text { Width }\end{array}$} & \multirow{2}{*}{$\begin{array}{c}\text { Average } \\
\text { Execution } \\
\text { Time (s) }\end{array}$} \\
\hline & Maximum & Mean & $\begin{array}{c}\text { Standard } \\
\text { Deviation }\end{array}$ & Maximum & Mean & $\begin{array}{c}\text { Standard } \\
\text { Deviation }\end{array}$ & & \\
\hline HPF & 0.110 & 0.110 & $1.38778 \mathrm{E}-17$ & 25.2 & 25.2 & 0 & 0.031 & 8.746373 \\
\hline BPF & 0.112 & 0.111 & $8 \mathrm{E}-8$ & 24.8 & 24.8 & 0 & 0.029 & 8.756441 \\
\hline
\end{tabular}

Table 5: Optimized coefficients for linear phase FIR filter of order 40

\begin{tabular}{|c|c|c|}
\hline $\mathbf{h}(\mathbf{n})$ & Coefficients for HPF & Coefficients for BPF \\
\hline $\mathrm{h}(1)=\mathrm{h}(41)$ & 0.0116506423040697 & 0.00732863691096892 \\
\hline $\mathrm{h}(2)=\mathrm{h}(40)$ & -0.0155043479180655 & $3.23348580450587 \mathrm{E}-06$ \\
\hline $\mathrm{h}(3)=\mathrm{h}(39)$ & -0.00340577555585417 & -0.0313559326354512 \\
\hline $\mathrm{h}(4)=\mathrm{h}(38)$ & 0.0183306985210835 & $-6.76532300792918 \mathrm{E}-06$ \\
\hline $\mathrm{h}(5)=\mathrm{h}(37)$ & -0.00493960900999834 & 0.0359306855792403 \\
\hline $\mathrm{h}(6)=\mathrm{h}(36)$ & -0.0189813713006128 & $-7.52002143487651 \mathrm{E}-07$ \\
\hline $\mathrm{h}(7)=\mathrm{h}(35)$ & 0.0139671176867423 & -0.00987927372863271 \\
\hline $\mathrm{h}(8)=\mathrm{h}(34)$ & 0.0169706962531505 & $2.82897491123325 \mathrm{E}-07$ \\
\hline $\mathrm{h}(9)=\mathrm{h}(33)$ & -0.023341793338269 & -0.0339954705310968 \\
\hline $\mathrm{h}(10)=\mathrm{h}(32)$ & -0.00945499629227418 & $3.11684799877311 \mathrm{E}-06$ \\
\hline $\mathrm{h}(11)=\mathrm{h}(31)$ & 0.0307847301379059 & 0.0633181934856963 \\
\hline $\mathrm{h}(12)=\mathrm{h}(30)$ & -0.000186212732706126 & 7.49070011911357E-07 \\
\hline $\mathrm{h}(13)=\mathrm{h}(29)$ & -0.0391481500899511 & -0.0437029528780699 \\
\hline$h(14)=h(28)$ & 0.0161055540447401 & $8.71870501962722 \mathrm{E}-07$ \\
\hline $\mathrm{h}(15)=\mathrm{h}(27)$ & 0.0452197355151915 & -0.0359122345639315 \\
\hline $\mathrm{h}(16)=\mathrm{h}(26)$ & -0.0415397666217645 & $-3.72917195603722 \mathrm{E}-06$ \\
\hline $\mathrm{h}(17)=\mathrm{h}(25)$ & -0.0511828075094237 & 0.152285804188384 \\
\hline $\mathrm{h}(18)=\mathrm{h}(24)$ & 0.0931103346205198 & $-6.08065886681956 \mathrm{E}-08$ \\
\hline $\mathrm{h}(19)=\mathrm{h}(23)$ & 0.0524256824687023 & -0.255472354346792 \\
\hline $\mathrm{h}(20)=\mathrm{h}(22)$ & -0.313308350901175 & $5.64594125887317 \mathrm{E}-06$ \\
\hline $\mathrm{h}(21)$ & 0.444755020716634 & 0.296759834612686 \\
\hline
\end{tabular}

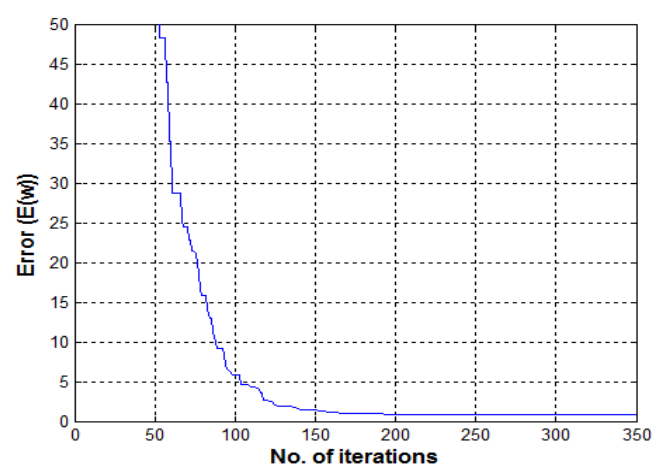

(a)

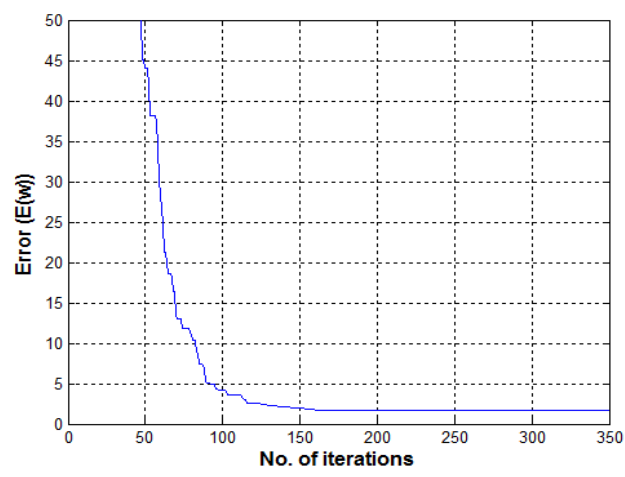

(b)

Fig. 6: Convergence behavior of PSO for linear phase (a) HP and (b) BP FIR filter of order 40

\section{CONCLUSION}

The present article extended the use of PSO algorithm with constriction factor approach, for design requirement of linear phase FIR filter with optimized transition width. Improvement in the transition width of designed FIR filter is studied with the changing filter order. FIR filter of order 30 and 40 is 
designed for HP and BP case for simulation study. The transition width of the designed FIR filter for order 40 is lesser than that of the FIR filter of 30, clearly stating that the performance characteristics of the filter improves with the order. The proposed algorithm is proved to be a highly effective and computationally fast tool for this sharp transitioning linear phase FIR filters design. However the study can be improved in future for the optimization of other performance parameters, such as stopband attenuation and passband ripples as well.

\section{DISCLOSURE}

The authors declare that there is no conflict of interest regarding the publication of this article.

\section{REFERENCES}

[1]. Oppenheim, A.V. and Schafer, R.W. (2002). Digital Signal Processing. New Delhi: Pearson Education.

[2]. Proakis, J.G. and Manolakis, D.G. (2000). Digital Signal Processing-Principles, Algorithms and Applications. New Delhi: Prentice-Hall.

[3]. Harris, F.J. (1978). On the use of windows for harmonic analysis with the discrete Fourier transform. IEEE Proceedings, 66, 51-83.

[4]. Rabiner, L.R., Herrmann, O. and Chan, D.S.K. (1973). Practical design rules for optimum finite impulse response of low pass digital filters. Bell System Technical Journal, 52(6), 769-799. Rabiner (1970). An approach to the approximation problem for Nonrecursive digital filters.

[5]. Parks, T.W. and McClellan, J.H. (1972). Chebyshev approximation for nonrecursive digital filters with linear phase. IEEE Transactions on Circuit Theory, 19(2), 189-194.

[6]. McClellan, J.H., Parks, T.W. and Rabiner, L.R. (1973). A computer program for designing optimum FIR linear phase digital filters. IEEE Transactions on Audio Electro acoustics, 21, 506-526.

[7]. Joaquim, M. B. and Lucietto, A.S. (2011). A nearly optimum linear-phase digital FIR filters design. Digital Signal Processing, 21, 690-693.

[8]. Lu, H.C. and Tzeng, S.T. (2000). Design of arbitrary FIR $\log$ filters by genetic algorithm approach. Signal Processing, 80, 497-505.

[9]. Radecki, J., Konrad J. and Dubois, E. (1995). Design of Multidimensional Finite-Word length FIR and IIR Filters by Simulated Annealing. IEEE Transactions on Circuits and Systems II: Analog and Digital Signal Processing, 42(6), 424-431.

[10].Karaboga, D., Horrocks, D.H., Karaboga, N. and Kalinli, A. (1997). Designing digital FIR filters using Tabu search algorithm. IEEE International Symposium on Circuits and Systems, 4, 2236-2239.

[11].Karaboga, N. (2009). A new design method based on artificial bee colony algorithm for digital IIR filters. Journal of the Franklin Institute, 4, 328-348.

[12].Karaboga, N. and Cetinkaya, B. (2006). Design of Digital FIR Filters Using Differential Evolution Algorithm. Circuits System Signal Processing, 25, 649660D.

[13].Kennedy, J. and Eberhart, R. (1995). Particle Swarm Optimization. Proceedings of IEEE International Conference on Neural Networks, 4, 1942-1948, Perth.

[14].Fang, W., Sun, J., Xu, W. and Liu, J. (2006). FIR Digital Filters Design Based on Quantum-behaved Particle Swarm Optimization. First International Conference on Innovative Computing, Information and Control, 615619, Beijing.

[15].Luitel, B. and Venayagamoorthy, G.K. (2008) Differential Evolution Particle Swarm Optimization for Digital Filter Design. IEEE Congress on Evolutionary Computation, 3954-3961, Hong Kong.

[16].Liu, G., Li, Y.X. and He, G. (2010). Design of Digital FIR Filters Using Differential Evolution Algorithm Based on Reserved Gene. IEEE Congress on Evolutionary Computation, 1-7, Barcelona.

[17].Mondal, S., Chakraborty, D., Kar, R., Mandal, D. and Ghoshal, S.P. (2012). Novel Particle Swarm Optimization for High Pass FIR filter Design. IEEE Symposium on Humanities, Science and Engineering Research, 413-418, Kuala Lumpur.

[18].Neha and Singh, A.P. (2014). Design of Linear Phase Low Pass FIR Filter using Particle Swarm Optimization Algorithm. International Journal of Computer Applications, 98(3), 40-44.

[19].Clerc, M. and Kennedy, J. (2002). The particle swarmexplosion, stability, and convergence in a multidimensional complex space. IEEE Transaction on Evolutionary Computation, 6(1), 58-73. 